\title{
Decentralized investment management: an analysis of non-profit pension funds
}

\author{
HAZEL BATEMAN* \\ University of New South Wales, Sydney \\ SUSAN THORP** \\ University of Technology, Sydney
}

\begin{abstract}
We investigate delegated investment management in private pension accounts using data from Australian accumulation (superannuation) funds. In Australian non-profit pension funds, trustees choose investment managers on behalf of members. We find that funds with many delegated managers have higher risk-adjusted returns than those with few. However funds with 13 or less specialized managers show no improvement over funds with a single diversified manager. All do worse than a benchmark portfolio of asset-class indices. Further, by using random selection to mimic the choices of an uninformed individual choosing from the same menu of delegate managers as used by trustees, we show that returns from pension funds with large numbers of trustee-selected managers compare favorably with returns from randomly selected, equally weighted portfolios. However this improvement falls off quickly for funds with fewer trustee-selected managers, or when randomly selected portfolios are also diversified across asset classes. Results indicate that an uninformed individual following a naive diversification strategy would have done as well as most trustee boards in this sample.
\end{abstract}

\section{Introduction}

As retirement income systems around the world move away from defined-benefit arrangements towards privately managed accumulation plans, participants are increasingly being compelled to make selections from menus of investment options. Consequently, issues of increasing concern in many countries are how pension fund investment menus are constructed and composed, and the degree of responsibility

Correspondence details: *Hazel Bateman, School of Economics, University of New South Wales, NSW 2052, Australia. Tel:+6129385 3096. Fax: +6129313 7691. Email: h.bateman@unsw.edu.au.

** Susan Thorp, School of Finance and Economics, University of Technology Sydney, Broadway NSW 2007, Australia. Tel: +6129514 7784. Fax: +6129514 7722. Email: susan.thorp@uts.edu.au.

We thank Tony Hall, Geoff Kingston, Robert Kohn, Olivia Mitchell, participants at the 13th Australian Colloquium of Superannuation Researchers, seminars participants at Queensland University of Technology and University of Technology Sydney, and anonymous referees for helpful comments. Alex Dunnin and colleagues at Rainmaker Information gave expert help with data and advice. The support of the Australian Research Council is gratefully acknowledged. 
falling to individual fund members for investment choice. Recent studies show that inadequate or poorly constructed investment menus can result in dramatic inefficiencies. ${ }^{1}$

A distinguishing feature of Australian arrangements is that among not-for-profit superannuation (private pension) funds, the choice of investment managers is delegated to trustees and their consultants. Individual members of superannuation funds allocate savings to investment managers indirectly through an entry-level choice from among multi-manager diversified and specialist asset allocation options. Trustees then pass the investment task on to groups of specialized investment managers. This practice raises questions as to the efficiency of direct, as opposed to delegated (or decentralized), choice of investment funds, a question of increasing urgency and relevance in many pension systems.

Here we report on patterns of delegated or decentralized investment choice in the Australian not-for-profit superannuation sector. We investigate whether this additional layer of management, where trustees pool contributions and then disperse them among selected investment managers, creates value for retirement savers. In particular we look for answers to four questions: Is there a pattern of increasing benefits to members as the number of delegated managers (mandates) increases? Can returns from the selected investment managers span a group of standard asset indices? Do trustees choose managers with more skill than an uninformed individual? Are benefits, if they exist, passed on to members' accounts via realized crediting rates?

Using new and unique data on almost two hundred not-for-profit private pension (superannuation) funds and their investment delegation patterns, we measure the relative performance of funds which delegate to many investment managers against the performance of similar funds which employ fewer managers, and against simple portfolio formation strategies. We find that funds where trustee boards employ a very large number of investment managers generate higher risk-adjusted returns over the (three-year) sample than other superannuation funds; results for funds with 13 or fewer mandates (managers) show no improvement over, and may do worse than, funds employing a single diversified manager. Returns from funds with large numbers of mandates compare favorably with returns from randomly selected portfolios, but this improvement falls off quickly for funds with fewer mandates, or when randomly selected portfolios are diversified across asset classes. Trustees' selections generally do not improve on the choices of an uninformed individual who randomly chooses one manager for each major asset class, then builds an equally weighted portfolio.

We begin with a review of the theory on decentralized portfolio management (Section 2), followed by a description of the current practices in investment delegation by not-for-profit superannuation funds (Section 3). Section 4 describes the database of superannuation fund investment portfolios we use for testing, outlines the empirical tests and presents results. Section 5 concludes.

1 See Elton, Gruber, and Blake (2004) and Brown and Weisbenner (2005). 


\section{Decentralized management in portfolio theory}

Inefficiency in decentralized management can arise from incomplete information transfer between the central manager and delegated managers. In a CAPM world, all investors observe the market portfolio's risk and return characteristics and can achieve maximum efficiency using two-fund separation. Where private information exists, however, investors may be able to generate returns above a passive benchmark by hiring well-informed active managers. In practice most active managers choose to accept direct control of a portfolio allocation rather than selling private information sets to clients because such information can easily be on-sold. At the same time central managers propose fee structures that are designed to reward accurate predictions and penalize mistakes by the active managers.

Nevertheless, the central manager must deal with the task of combining delegated portfolio subsets into an efficient centralized portfolio. Most of the literature on decentralized portfolio management investigates rules and incentive structures which a central manager can use to achieve efficiency when not privy to the full information set of the delegate managers.

Sharpe (1981) defines the decentralized portfolio selection process as an extra level of diversification. He distinguishes diversification of judgment where a central manager selects more than one delegated manager to mitigate any serious individual prediction errors, but where delegated managers can choose from all available securities, and diversification of styles, where delegated managers analyze a discrete subset of securities. The potential for selecting efficient centralized portfolios varies with these different types of diversification. ${ }^{2}$

Sharpe derives efficient myopic decision rules under three conditions: firstly, passive and active delegated managers analyze an overlapping set of securities; secondly, all managers agree on covariance predictions; and, thirdly, any delegated manager predicts each element of the set of returns with the same level of accuracy. If these conditions hold, the central manager diversifies across judgments by combining delegated manager portfolios according to their assessment of each delegate's general predictive accuracy. The resulting combined portfolio is efficient under myopic rules: each active manager simply chooses a minimum variance portfolio subject to their own predictions, the passive manager chooses a minimum variance portfolio subject to consensus predictions, and the central manager creates a weighted average of all delegated portfolios depending on their personal evaluation of each active manager's accuracy. To make this work, the central manager does not need to know active predictions of individual portfolio returns.

If the problem is restricted to the case where managers optimize over nonoverlapping subsets of securities (i.e. diversification of style), Sharpe argues that myopic decision rules are usually not optimal, even where there is consensus about the covariance of asset returns. A first-best outcome cannot be attained in one step, and he proposes a two-step process, where one active manager myopically optimizes over the subset, and the second active manager is compelled to consider the return

\footnotetext{
${ }^{2}$ Sharpe restricts analysis to the case where managers disagree about expected returns but hold a consensus estimate of covariance.
} 
and variance of their own portfolio along with its covariance with the remaining portfolio (that part due to manager one). However this two-step process may be simplified if security returns are well described by a factor model, as more recent literature shows.

Elton and Gruber (2004) present an extension and generalization of Sharpe's analysis. ${ }^{3}$ They view the centralized decision maker as a mean-variance optimizer who believes that security returns are generated by a set of indices that can be held as passive portfolios. The central decision maker can build an optimal aggregate portfolio if active managers are required to hold securities in proportion to their alpha-to-non-systemic-risk ratio. As long as active managers will tell the central manager their estimate of alpha for their whole active portfolio, the residual risk of the active portfolio, and the sensitivities (betas) of the active portfolio relative to the indices, the central manager can construct an efficient portfolio as a weighted combination of optimal active and passive portfolios.

Here the central manager can combine overlapping and/or bounded active portfolios without being told specific security return forecasts and without a complete consensus on covariance. This is possible because of the key feature of the system: an index-based returns process, summarizing covariance information for all investors in terms of two (or more) passive indices.

Despite the theoretical complexity of coming up with efficient multi-layer portfolios, there are clear trends in the Australian retirement savings system towards decentralized investment. In this study we do not aim to extend the theory of decentralized management, but rather to unravel the strands of delegation by which retirement savings in Australia are invested, and to evaluate the effectiveness of delegation by a series of performance and efficiency measures. Section 3 sketches the features of decentralized management in the Australian pension system.

\section{Decentralized management in private pension funds}

While pension plan participants are increasingly required to make decisions about how their assets will be allocated across a menu of investment choices, current practice in relation to the responsibility for the menu and its composition differs widely.

Under the voluntary company-sponsored $401(\mathrm{k})$ plans prevalent in the United States, plan participants are generally offered direct choice among a range of specific investment funds. ${ }^{4}$

Plan sponsors (generally employers) and/or plan administrators decide on the menu of investment funds and plan participants allocate their assets across the investment funds offered. The regulatory requirements encourage sponsors to provide a diverse

\footnotetext{
3 Treynor and Black (1973) derive a CAPM beta model of delegated management.

4 The adequacy and characteristics of investment funds offered to $401(\mathrm{k})$ participants is analyzed by Elton, Gruber, and Blake (2004). They find that for $62 \%$ of plans, the menus offered are inadequate and that over a 20 -year period, this would make a difference in terminal wealth of over $300 \%$. They also find that the investment funds included in the $40(\mathrm{k})$ plan menus are riskier than the general population of funds in the same categories, but that the funds included in the plans outperform a menu of randomly selected funds.
} 
offering and require that participants be able to 'exercise independent control' over assets in the account. ${ }^{5}$

A minimum of three investment options must be offered, each with different risk/ return characteristics. Recent surveys of $401(\mathrm{k})$ plans indicate that the median number of investment choices is around 10-12 and that the investment funds generally cover the standard range of asset classes (Elton, Gruber, and Blake, 2004; Papke, 2004; Mitchell, Utkus, and Yang, 2005). With recent proposals for the reform of US Social Security emphasizing personal retirement accounts (Cogan and Mitchell, 2003), there has been considerable interest in the menu of investment options in 401(k) plans and its impact on participant choice (Brown and Weisbenner, 2005). ${ }^{6}$

Since 2000, public pension participants in Sweden have been required to place 2.5 percentage points of their mandatory Premium Pension contributions into individual accounts. This mandatory retirement saving is organized on a national basis, with a government agency (the PPM) set up to administer the plan and act as a clearinghouse. Subject to regulatory requirements, which include some restrictions on fee structure, any investment company licensed to do business in Sweden is allowed to participate in the system. The menu of investment funds offered to participants has grown from 460 at commencement in 2000, to over 650 by 2004. From this menu of (mostly specialized) investment funds, plan participants construct a portfolio of up to five investment funds or opt for the default fund. Over $70 \%$ of current participants have made 'active' choices (Sunden, 2004; Palme, Sunden, and Sonderlind, 2005).

In Australia, the mandatory superannuation guarantee requires employers to contribute at least $9 \%$ of employees' incomes into a superannuation (pension) fund. ${ }^{7}$

Initially, choice of superannuation fund - the trustee structure responsible for the management and investment of superannuation assets - lay with employers, but, since July 2005, choice of superannuation fund has been available to employees. Irrespective of who chooses the superannuation fund, participant investment choice within a given superannuation fund is both prevalent and increasing. Around $85 \%$ of superannuation assets are in superannuation funds offering investment choice.

The Australian superannuation industry is characterized by considerable diversity of design and management and this is reflected in the extent and composition of investment choice. The industry can be categorized into three fund types - 'retail' superannuation funds, 'not-for-profit' superannuation funds and 'self-managed' superannuation funds. As of March 2005, these accounted for $34 \%, 43 \%$, and $23 \%$ of total superannuation assets respectively. In terms of investment choice, selfmanaged funds allow unlimited choice of investment funds, retail funds generally offer choice across single manager specialized investment funds, while not-for-profit superannuation funds offer, as a minimum, choice across multi-manager diversified portfolios (typically classified by the standard options of 'cash', 'capital stable', 'balanced', 'growth', etc.). At March 2005, retail funds offered an average choice of

\footnotetext{
${ }^{5}$ Under section 404(c) of ERISA, a sponsor of a 401(k) plan is not liable for loss or breach of fiduciary responsibility that may result from the participant's exercise of control over assets.

6 The US President's 2005 State of the Union address highlighted the need for social security reform and the benefits of individual accounts with participant-directed investments.

7 'Superannuation' is the commonly used term in Australia for private pensions.
} 


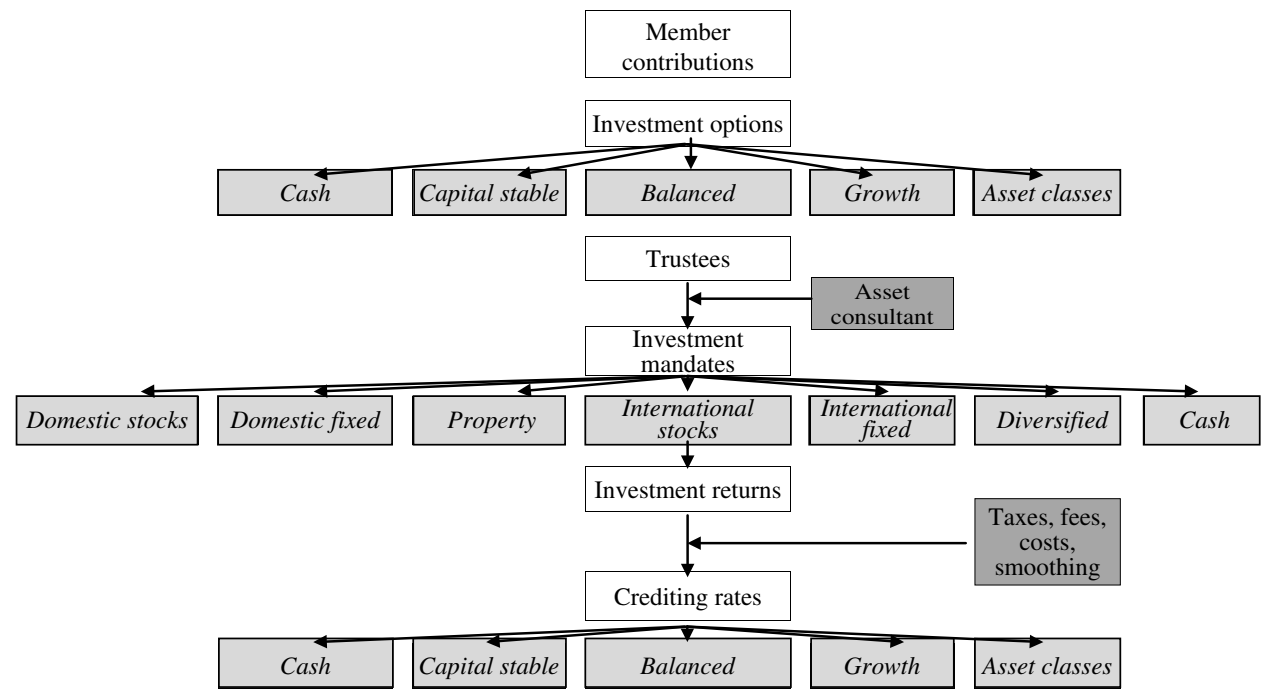

Figure 1. Structure of decentralized management in non-profit superannuation funds

59 mainly specialized investment funds, while non-profit funds offered choice of seven mainly multi-manager diversified portfolios (APRA, 2005). ${ }^{8}$

In terms of investment management structures, self-managed and retail funds typically allow members to directly allocate contributions among a menu of (mutual fund) managers and consequently resemble more closely 401(k) plans in the US and Premium Pensions in Sweden. By contrast, the majority of non-profit funds operate an additional layer of investment management via the trustee boards. The remainder of this paper considers the non-profit sector only.

Superannuation funds operate as trusts and are managed by boards of trustees, which, for the non-profit sector, are generally required to comprise equal employee and employer representation. While the duties of trustees include administration, regulatory compliance, and communication with members, their foremost task is efficient investment. Legislation specifically requires trustees to implement an investment strategy that 'has regard to ... the composition of the fund's investments as a whole including the extent to which the investments are or are not diversified and the associated risks' (APRA, 1999, II.D.1). Hence trustees are expected to coordinate the choices offered to members and the underlying investment mandates. (From now on we use the term 'trustee' to denote the central investment manager of a non-profit superannuation fund, and 'manager' to denote a contracted investment agent of the trustee.)

Figure 1 illustrates a stylized example of investment choices offered to members of Australian not-for-profit superannuation funds through a number of multi-manager

8 There are, of course, many exceptions to these generalizations. For example, in 2004, the not-for-profit industry superannuation fund REST offered choice across both multi-manager diversified options and multi-manager by asset class; the not-for-profit industry fund Sunsuper offered choice across single and multi-manager diversified and specialized options; and the retail superannuation fund AMP Flexible Lifetime Super offered choice across single- and multi-manager diversified and specialized options (Bateman and Hill, 2004). 
diversified options: cash, capital stable, balanced, or growth (reflecting increasing exposure to riskier asset classes). Many superannuation funds also allow individuals to design their own combination of specific asset classes, rather than a 'pre-mixed' option. Prospectuses for new members commonly display charts or tables showing the benchmark asset class weightings underlying each type of account alongside descriptions of account options. Balanced options, which typically cover domestic and international fixed interest, equities and cash, are the most popular choice, and also the most common default (in the event that a new member makes no active selection).

When members select an investment option, they are instructing trustees on how their individual accounts should be invested. Once contributions are in the hands of trustees, however, any clear delineation between account options is submerged into the mandates comprising the superannuation fund's investment pool.

In most cases, trustees will engage an asset consultant to advise on the choice of managers, investment strategies, and allocations. Sometimes, under implemented consulting arrangements, the asset consultant also engages the investment managers for the superannuation fund. Having formulated a strategy, trustees then issue contracts or 'mandates' to managers, setting out specific instructions, performance standards and fees, as noted above. Under current practice, mandates are usually specified over a three- to four-year contract period.

This portfolio of investments managed under mandates generate returns that are eventually passed on to members as crediting rates to their chosen investment options after deductions for taxes, fees, expenses, and smoothing.

Delegated investment management is increasing and becoming more specialized (Rainmaker, 2004). Whereas diversified mandates instruct the manager to invest across a range of asset classes, specialized mandates restrict the manager to a designated area of expertise, usually an asset class, subclass, and/or 'style'. The responsibility to monitor and manage risk, and diversify effectively, remains with trustees, even when parts of the investment portfolio are managed under a mandate. The investment mandates are themselves regulated, and must include explicit investment constraints, performance, or benchmark standards, reporting and auditing standards, fees and charges schedules, as well as dispute resolution procedures and termination conditions. However mandates are confidential documents and a superannuation fund's underlying investment strategies and fee structures at the level of individual mandates are not disclosed to members. Most fund members must rely on trustees' reports, for investment and fee information.

Rainmaker's (2004) survey of the delegated investment (mandates) for 269 not-forprofit superannuation funds, encompassing \$204 billion funds under management (FUM) and including government, industry, and corporate funds identified a number of clear trends in mandates. Notably, the majority of FUM in mandates are invested through delegated managers (93\% of the total FUM in the survey), with an average of 22 mandates per manager and an average mandate size of $\$ 65$ million. The average number of mandates per superannuation fund has doubled over the past six years to 12 , but some funds issue many more mandates (over 50). Not surprisingly, large superannuation funds issue more mandates than small funds (at a ratio of about four 
to one), and funds employing asset consultants issue about twice as many mandates as those which do not.

The trend towards specialized mandates is evident with the percentage of diversified mandates (covering a range of asset classes and styles) falling from 50 to 15 over the past six years.

Asset consultants play a crucial role in the delegated management process, and the consulting industry is becoming more concentrated. While there are 22 asset consultants advising Australian superannuation funds, the ten largest consulting firms control $97 \%$ of the funds under asset consultant advice. In addition, the number of asset consultants has almost halved in the past five years as consultants themselves specialize in the types of superannuation funds they advise.

In comparing the Australian non-profit superannuation funds with international experience, we see that the non-profit funds typically use an additional layer of investment management so that the investment decisions of members pass through two layers of delegation. At one level, members can choose to allocate their assets/ contributions across a number of multi-manager diversified portfolios. But at the next level, decisions about the investment managers (mandates) operationalizing these choices are made by trustees and their consultants.

\section{Empirical evaluation}

We look at the question of decentralized management efficiency from two perspectives: we first compare the performance of one non-profit fund against another, gathering information on whether there are measurable differences between them according to the number of mandates they issue; then we compare existing funds against a number of performance standards, via a series of spanning tests and simulations.

\subsection{Data}

There is no official collection of data on delegated investment patterns among pension funds in Australia. However, Rainmaker Information, ${ }^{9}$ a private, industry research house, collects data on a wide range of fund characteristics, including mandate patterns, for not-for-profit superannuation funds, representing around $90 \%$ of the not-for-profit share of the superannuation sector. These data are self-reported by the superannuation funds to Rainmaker at quarterly frequency and collected into a proprietary electronic database which is marketed by subscription to interested researchers. We selected 198 of the funds represented in the 2004 database on the basis of the size of funds under management and the mandate record's coverage of the fund's total portfolio allocation. The mandate records show the percentage of each fund's portfolio allocated to a specific manager. ${ }^{10} \mathrm{We}$ hold patterns of allocation derived from the mandate data constant throughout the three-year sample, since for

${ }^{9}$ Rainmaker (2004) provides a more detailed description of the mandate database.

${ }^{10}$ For 12 funds in our sample, we had records of the managers employed by the fund but not the proportion of assets allocated to each manager. We assumed that assets were allocated equally among managers for these funds. 


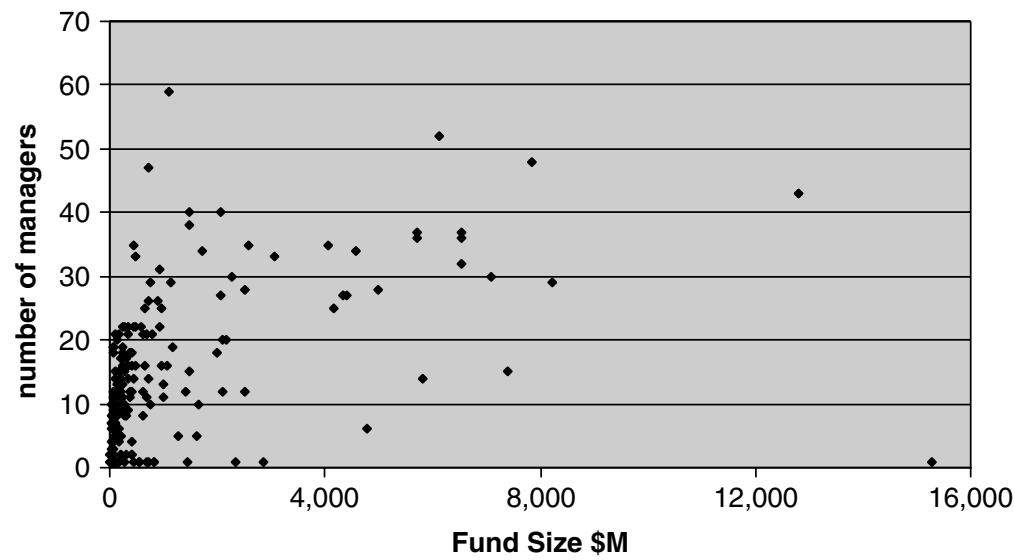

Figure 2. Mandate number and size of superannuation fund

our sample we have only one set of mandate records currently available and in any case the average length of a mandate contract is three years.

The number of mandates per fund in our sample ranges from 59 to 1 . The first, second, and third quartile markers for the mandate distribution fall at 5, 12, and 21 mandates, so for the purposes of easier comparison, we also divide the funds into four (unequal) groups. The first group includes 45 funds with 22-59 mandates, the second includes 46 funds with 13-21 mandates, the third group includes 52 funds with 6-12 mandates, and the fourth group includes 55 funds with 1-5 mandates.

Size of fund and mandate number are positively correlated $(\rho=0.46)$ as is evident in Figure 2, but there are a number of large funds with few mandates and vice versa.

In addition, Rainmaker supplied historical monthly returns data for 468 specialized and diversified investment funds, encompassing most of the managers employed by superannuation fund trustees from January 2002 to December 2004. In the Rainmaker database, mandates are identified by manager name and asset class. The 11 separate asset class identifiers which Rainmaker uses are representative of the investment patterns of Australian superannuation funds according to official statistical collections (see APRA, 2005). Where possible, we make a precise match between mandate and manager; an exact match is possible with $61 \%$ of mandates. Where we cannot make a precise match, we substitute a proxy return based on an average return to all managers in that asset class, or, in the case of cash and private equity, we substitute an index return. In addition, since diversified fund returns are reported net of fees but specialized funds are not, we add back the equivalent of $0.5 \%$ per annum to returns to diversified funds to account for fee deductions. Hence all manager returns (and therefore fund returns) are reported gross of all investment fees. Table 1 sets out the asset classes and proxies.

We combine mandate weights and manager returns to compute a monthly portfolio return for each of the 198 superannuation funds, for the sample period January 2002 to December 2004 (a total of 36 observations for each fund). Superannuation 
Table 1. List of proxies for non-matching mandates

\begin{tabular}{|c|c|c|c|}
\hline Asset Class & $\begin{array}{l}\text { Number of } \\
\text { Managers }\end{array}$ & Proxy & $\begin{array}{l}\text { Sample average } \\
\text { return, p.a. }\end{array}$ \\
\hline Australian Equity & 114 & Average of managers & $7.58 \%$ \\
\hline Australian Fixed & 47 & Average of managers & $1.39 \%$ \\
\hline Property & 49 & Average of managers & $11.30 \%$ \\
\hline International Equity & 121 & Average of managers & $-7.64 \%$ \\
\hline International Fixed & 26 & Average of managers & $3.43 \%$ \\
\hline Hedge & 5 & Average of managers & $13.75 \%$ \\
\hline Diversified & 107 & $\begin{array}{l}\text { Average of balanced } \\
\text { diversified managers }\end{array}$ & $5.61 \%$ \\
\hline Private Equity & - & $\begin{array}{l}\text { Datastream Australian } \\
\text { small cap equities index }\end{array}$ & $12.65 \%$ \\
\hline Cash & - & $\begin{array}{l}\text { Datastream Bank } \\
\text { Bills index }\end{array}$ & $4.99 \%$ \\
\hline Foreign Currency & - & Assumed zero & $0 \%$ \\
\hline Other & - & $\begin{array}{l}\text { Average of balanced } \\
\text { diversified managers }\end{array}$ & $5.61 \%$ \\
\hline
\end{tabular}

fund portfolio returns are therefore a mandate-weighted average of the manager returns and/or its proxies. ${ }^{11}$

\subsection{Do risk-adjusted returns rise with the number of delegated managers?}

We begin by looking at the return and risk profile of each of the 198 individual funds in the sample, listed by the number of mandates they issue, then review the performance of the four quartile groups where group 1 has the most and group 4 the least mandates. We assume that the aim of superannuation funds in issuing mandates is to improve risk-adjusted return (net of fees) to investment, either through diversification of judgment, so that negative impacts from prediction errors of any single active manager are lessened by adding managers to the central fund, and/or through diversification of style, so that the active skills of specialist managers are combined. If these strategies are effective, we would expect to see smoother and higher returns among funds issuing more mandates.

It is natural to expect that costs are higher for superannuation funds with more mandates, due to the higher administrative costs of tendering for, and keeping track of, more mandates. We also expect higher investment fees as greater specialization and expertise are required from managers, and as the superannuation fund assets are broken down into smaller sub-groups, possibly lowering economies of scale. We currently do not have the relevant data to address these important issues so we restrict our investigation to returns comparisons. To the extent that differences between investment returns and crediting rates to members' accounts are a guide to fees and costs, some indication is provided in Section 4.5.

${ }^{11}$ We therefore cannot claim that our calculated returns match the true gross returns to any fund precisely. 


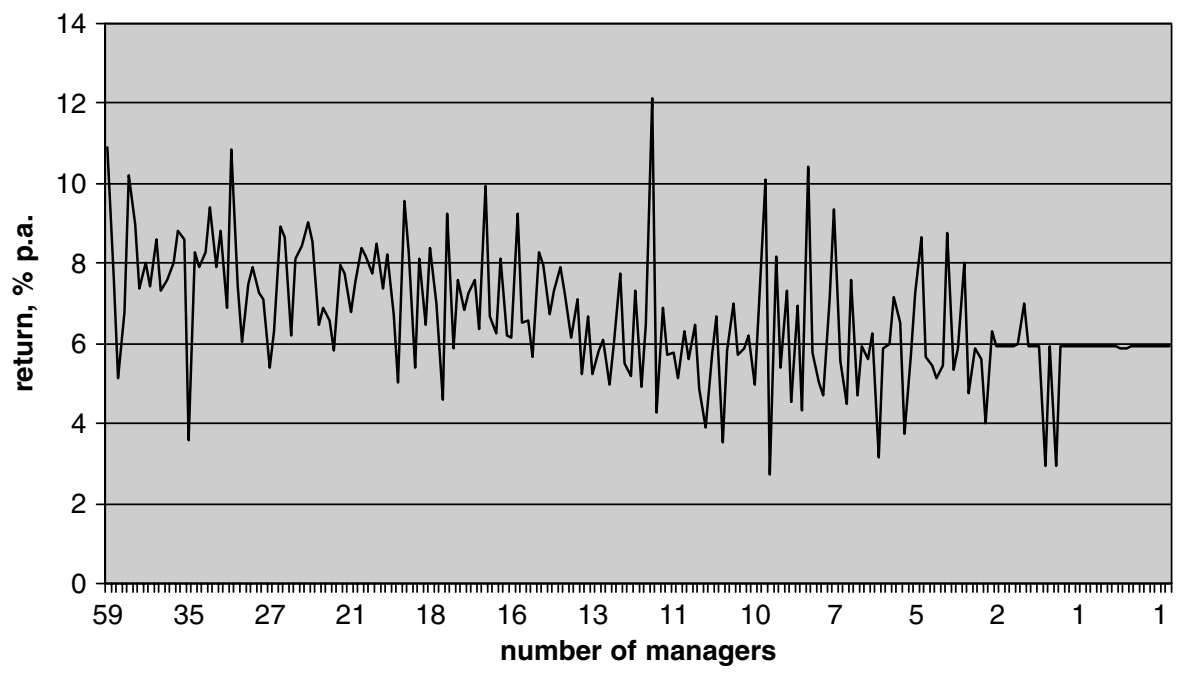

Figure 3. Average annual investment returns to individual superannuation funds

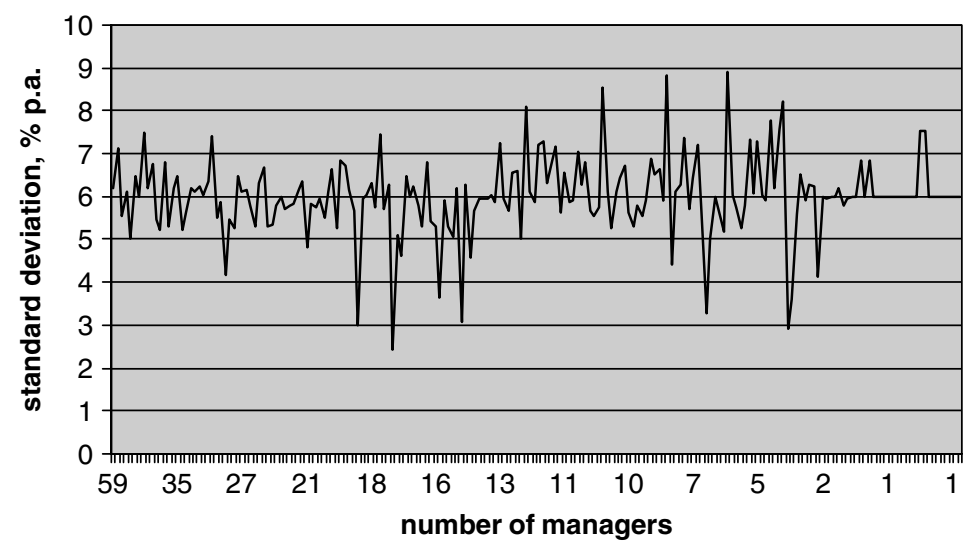

Figure 4. Standard deviation of monthly individual superannuation fund returns

\section{Individual funds}

Figure 3 shows average annual investment returns over the three years to December 2004 for all 198 non-profit superannuation funds. The average annual return across all funds in the sample was $6.65 \%$, with the highest return above $12 \%$ and the lowest return under $3 \%$. The mean return appears to decline as mandate numbers decrease, suggesting that mandate numbers are positively correlated with investment returns. (This result will be shown more precisely when we review group performance below.)

Risk levels do not show a clear trend (Figure 4), being centered on an average of $6 \%$ p.a., with the most risky fund showing a standard deviation slightly below $9 \%$, and the least risky, a standard deviation close to $2.5 \%$. Funds in the 6-12 mandates range have the highest risk, while funds in the 13-21 mandates range have the least. 


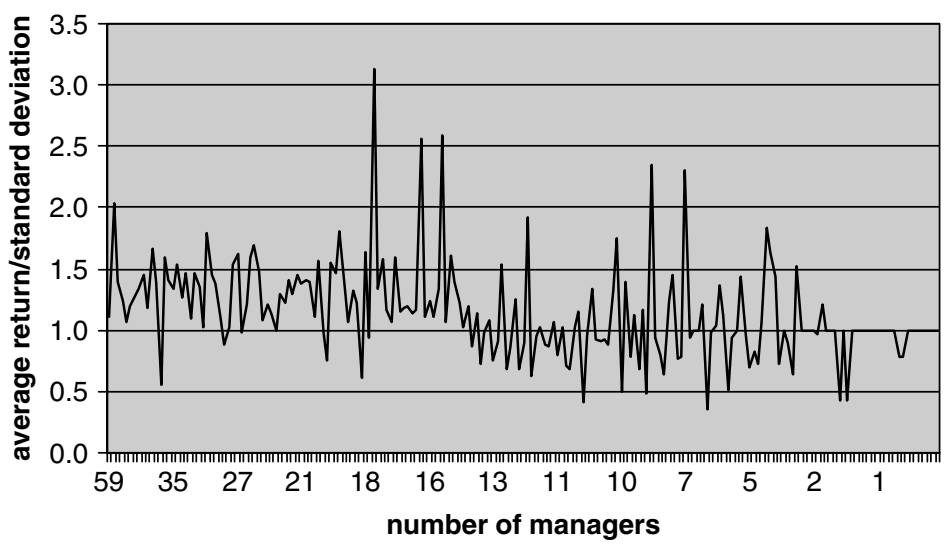

Figure 5. Ratio of annual return to standard deviation by individual superannuation fund

Figure 5 illustrates the return to risk ratios, showing a small downward trend and/or break around the 12 mandates mark, and indeed the average return to risk ratio for funds with more than 12 mandates is 1.3 , while the average for funds with 12 or fewer is 1.0 .

Overall fund with fund comparison points to benefits from diversifying across more manager mandates. However, the returns and risk are not linearly related to number of mandates, since the most unpredictable and potentially poor outcomes are in the 6-12 mandates region, and the best risk-adjusted outcomes are in the 13-21 mandates region.

\section{Grouped funds}

The small number of time series observations available for each superannuation fund portfolio makes more rigorous testing difficult at the individual fund level. We would like to take the testing further, so we arbitrarily divide the funds into approximate quartiles (as outlined in Section 4.1), stacking returns for all the funds in each division, and artificially creating four series of portfolio returns. ${ }^{12}$ Table 2 sets out summary statistics for each of the four groups of funds. Mean returns are highest for the funds with the most mandates and least for the funds with the least mandates, but standard deviations do not decline evenly as mandate numbers increase: the 13-21 mandate group is least risky, and the 6-12 mandate group is most risky. Negative skewness (indicating a long left tail in the returns distribution) gets worse as mandate numbers increase from 6 to 59, but kurtosis seems unrelated to mandates. ${ }^{13}$

One implication of diversification across managers is that returns should be less volatile as trustees diversify across specialists. To formally compare the volatility of different mandate groups we test for significant difference between realized volatilities. We compute portfolio realized variances as squared excess returns $\left\{\left(\mu_{t}^{i}\right)^{2}\right\}_{i=1}^{4}$

${ }^{12}$ Stacking returns in blocks preserves temporal dependence across the four groups.

${ }^{13}$ In a related study into equity fund of funds in Australia, Brands and Gallagher (2003) find that negative skewness and kurtosis worsen as managers are added to a fund of equity funds. 
Table 2. Summary statistics, pooled monthly returns, annualized

Statistics calculated from annualized monthly returns for all superannuation funds in each group. Group 1 includes 1620 observations, Group 2 includes 1656, Group 3 includes 1872, and Group 4 includes 1980 observations.

\begin{tabular}{|c|c|c|c|c|}
\hline & Group 1 & Group 2 & Group 3 & Group 4 \\
\hline & $\begin{array}{c}22-59 \\
\text { Mandates }\end{array}$ & $\begin{array}{c}\text { 13-21 } \\
\text { Mandates }\end{array}$ & $\begin{array}{c}\text { 6-12 } \\
\text { Mandates }\end{array}$ & $\begin{array}{c}1-5 \\
\text { Mandates }\end{array}$ \\
\hline Mean & 9.87 & 9.17 & 8.45 & 8.14 \\
\hline Median & 12.61 & 11.46 & 11.07 & 11.17 \\
\hline Std. Dev. & 6.08 & 5.82 & 6.30 & 6.18 \\
\hline Reward to risk & 1.62 & 1.58 & 1.34 & 1.32 \\
\hline Skewness & -0.32 & -0.28 & -0.24 & -0.31 \\
\hline Kurtosis & 2.32 & 2.36 & 2.32 & 2.31 \\
\hline
\end{tabular}

Table 3. Difference in portfolio variance, Groups $1-4$

Estimated coefficients in the regression of $\mu_{i j}$ on a constant, where $\mu_{i j}$ is the difference between realized volatility of portfolio $i$ and portfolio $j$ at each observation. A significant positive value indicates that the variance of portfolio $i$ exceeds the variance of portfolio $j$. A significant negative value indicates that the variance of portfolio $i$ is smaller than the variance of portfolio $j$. $t$-statistics are based on robust (Newey-West) standard errors.

\begin{tabular}{|c|c|c|c|c|c|c|}
\hline \multirow[b]{3}{*}{ Portfolio $j$} & \multicolumn{6}{|c|}{ Portfolio $i$} \\
\hline & \multicolumn{2}{|c|}{ 1-5 Mandates } & \multicolumn{2}{|c|}{ 6-12 Mandates } & \multicolumn{2}{|c|}{ 13-21 Mandates } \\
\hline & Coefficient & $t$-stat & Coefficient & $t$-stat & Coefficient & $t$-stat \\
\hline 6-12 Mandates & -0.056 & -0.496 & & & & \\
\hline 13-21 Mandates & 0.457 & 3.880 & 0.648 & 6.182 & & \\
\hline 22-59 Mandates & 0.179 & 1.806 & 0.383 & 4.048 & -0.281 & -3.061 \\
\hline
\end{tabular}

at each time period, $t$, in the sample, for each of the groups $i=1, \ldots, 4$. Returns are net of the 30-day risk-free rate for $t$. For each possible pairing of groups $(i j)$, we then compute the difference

$$
\mu_{t}^{i j}=\left(\mu_{t}^{i}\right)^{2}-\left(\mu_{t}^{j}\right)^{2}, i \neq j
$$

forming $\left\{\left(\mu_{t}^{i j}\right)\right\}_{i, j=1, i \neq j}^{4}$.

The null hypothesis is that the mean of each $\left(\mu_{t}^{i j}\right)$ series is zero, indicating that no reduction in portfolio volatility accrues as mandates are added to portfolios. We test this hypothesis by a $t$-test on the coefficient $\beta$ in the regression $\mu_{t}^{i j}=\beta \iota+\varepsilon_{t}$ where $\iota$ is a vector of ones (Table 3 ). The first column reports tests of volatility of group 4 less volatility of groups 3,2 , and 1 . Positive values indicate that the variance of group 4 is 


\section{Table 4. Tests for second degree stochastic dominance, Groups 1-4}

Test that portfolio $i$ dominates portfolio $j$ in the second degree in the left-hand column and corresponding test that portfolio $j$ dominates portfolio $i$ in the right-hand column. A high p-value indicates failure to reject the null hypothesis that $i$ dominates $j$ (or the reverse). Significant p-values are marked with an asterisk.

\begin{tabular}{|c|c|c|c|c|c|c|}
\hline \multirow[b]{3}{*}{ Portfolio $j$} & \multicolumn{6}{|c|}{ Portfolio $i$} \\
\hline & \multicolumn{2}{|c|}{ 1-5 Mandates } & \multicolumn{2}{|c|}{ 6-12 Mandates } & \multicolumn{2}{|c|}{ 13-21 Mandates } \\
\hline & p-value & p-value & $\mathrm{p}$-value & p-value & p-value & p-value \\
\hline 6-12 Mandates & 0.12 & 0.46 & & & & \\
\hline 13-21 Mandates & $0.00 * *$ & 0.88 & $0.00 * *$ & 0.82 & & \\
\hline 22-59 Mandates & $0.00 * *$ & 0.89 & $0.00 * *$ & 0.83 & $0.03 *$ & 0.26 \\
\hline
\end{tabular}

larger than the comparison group, and negative values indicate the reverse. Significantly smaller variances are obtained in the two largest mandate groups, but there is no significant volatility difference between groups 3 and 4. Funds with 13-21 mandates have smaller volatility than funds with 22-59 mandates, as shown by the significant negative coefficient in the last column. Overall, the least risky returns are obtained in the 13-21 mandate range, with no significant reduction in risk from more mandates. In addition, moving from the $1-5$ to the $6-12$ range creates no significant improvement for investors.

Retirement savers are interested in both return and risk, so we shift focus to tests of stochastic dominance. Our aim is to test whether differences between realized portfolio returns are likely to matter to a risk-averse investor, or whether in fact investors would be indifferent between the groups. For any two samples of portfolio returns $\left\{\mu^{i}\right\}$ and $\left\{\mu^{j}\right\}$ with cumulative distributions (CDFs) $G$ and $F$, portfolio $i$ will be preferred by portfolio $j$ by any agent whose utility over returns exhibits risk aversion (so that $U(\mu)$ obeys $U^{\prime}(\mu) \geqslant 0$, and $U^{\prime \prime}(\mu) \leqslant 0$ ) when $\int_{0}^{\mu} G(t) d t \leqslant \int_{0}^{\mu} F(t) d t$ for all $\mu$. The null hypothesis to be tested is that $G$ weakly dominates $F$ in the second degree. The CDFs are evaluated at all points in the support. ${ }^{14}$ Under the null hypothesis, the test statistic is no greater than zero. The sampling distribution of the test statistic is generated by a block bootstrap. ${ }^{15}$

Table 4 reports test results. We establish the dominance of portfolio returns $i$ over $j$ when the null hypothesis is accepted for $i$ tested against $j$ but rejected when the hypothesis is reversed. If we can reject neither null, the test is inconclusive. Returns from the 22-59 mandates group dominate returns from all other groups, and would be preferred by risk-averse agents. Group 2 is also clearly preferred to the fewmandates groups, but we found no clear ordering over returns to the 1-5 and 6-12 groups.

${ }^{14}$ We refer the reader to Barrett and Donald (2003) for an explicit discussion of the test statistic and its sampling distribution.

${ }^{15}$ We use the block bootstrap method of Lim, Maasoumi, and Martin (2004) to allow for contemporaneous and serial dependence in the data, with block size $\sqrt{ } T$, where $T$ is the number of observations. 
Table 5. Summary statistics for asset class indices, annual, January 2002-December 2004

\begin{tabular}{|c|c|c|c|c|c|c|c|c|}
\hline & & Mean & Median & $\begin{array}{c}\text { Standard } \\
\text { Dev. }\end{array}$ & Max & Min & Skewness & Kurtosis \\
\hline \multicolumn{9}{|l|}{ Australian } \\
\hline \multirow[t]{5}{*}{ Equities } & Large-cap & 5.83 & 5.38 & 12.24 & 27.14 & -16.52 & -0.01 & 1.90 \\
\hline & Mid-cap & 17.97 & 19.78 & 11.13 & 43.84 & -1.65 & 0.06 & 2.37 \\
\hline & Small-cap & 12.65 & 13.42 & 16.51 & 38.96 & -14.37 & -0.08 & 1.62 \\
\hline & Value & 6.07 & 5.90 & 10.95 & 27.65 & -11.95 & 0.20 & 2.10 \\
\hline & Growth & 6.82 & 8.60 & 14.19 & 28.98 & -19.60 & -0.13 & 1.79 \\
\hline Property & Listed & 16.23 & 14.40 & 6.83 & 32.39 & 7.72 & 1.11 & 3.22 \\
\hline \multirow[t]{2}{*}{ Fixed interest } & Composite & 5.72 & 5.14 & 2.51 & 11.05 & 2.05 & 0.42 & 2.09 \\
\hline & Indexed & 7.20 & 6.83 & 3.05 & 14.61 & 2.27 & 0.36 & 2.42 \\
\hline Cash & Bank Bills & 4.99 & 4.92 & 0.29 & 5.62 & 4.63 & 0.88 & 2.66 \\
\hline \multicolumn{9}{|l|}{ International } \\
\hline \multirow[t]{2}{*}{ Equities } & World & -8.17 & -10.19 & 16.49 & 20.66 & -33.27 & 0.11 & 1.58 \\
\hline & Emerging & 5.61 & 5.85 & 18.28 & 40.71 & -28.01 & -0.04 & 2.30 \\
\hline Fixed interest & Government & 8.01 & 7.31 & 2.74 & 14.25 & 2.92 & 0.55 & 2.70 \\
\hline
\end{tabular}

Comparing group with group shows advantages to members of funds who invest in 13 or more managers. These funds show significantly less volatility and overall higher returns than the funds choosing less than 13 mandates. However at the lower end of the spectrum, no significant advantages accrue to member of funds who choose between 6-12 managers rather than a small number, or even one, diversified manager.

\subsection{Do decentralized funds do better than standard index returns?}

The essence of performance assessment is to "investigate whether a fund manager helps enlarge the investment opportunity set faced by the investing public and, if so, to what extent the manager enlarges it' (Chen and Knez, 1996). To make this measurement we need to test the funds here against a benchmark or proxy for the investment opportunity set faced by an unrestricted superannuation investor or trustee, rather than simply comparing one fund against another. ${ }^{16}$

\section{Benchmark selection}

Our goal in choosing a benchmark is to span as efficiently as possible the investment opportunity set faced by trustees. As a minimum we expect that the portfolios offered by superannuation trustees should be as efficient as one which any well-informed trustee could construct from the universe of available mutual funds. Following Elton, Gruber, and Blake (2004), we choose a set of asset class indices as a proxy for passive investment in well-diversified portfolios of equities, property, fixed interest, and cash. (Table 5 gives summary statistics, and a full description of sources is given in Appendix A.) We include both domestic and international equities and fixed interest

${ }^{16}$ As noted earlier, the option of direct investment of retirement saving into passive index funds is available to Australians who are members of retail and/or self-managed superannuation funds. 
indices: we divide domestic equities by size and value/growth divisions, and domestic fixed interest securities into composite and indexed classes. Of the asset-class indices tested, listed property has the highest average, and world equity markets the lowest average returns over the sample. Returns to these indices represent gross investment returns to well-diversified investments in each asset class before fees. Since the superannuation fund returns are also gross of fees, index returns are comparable. The asset classes making up the benchmark are representative of the investment patterns of Australian superannuation funds according to official statistical collections (see APRA, 2005).

\section{Spanning tests: mandate funds}

The set of benchmark returns is used in two sets of tests. Firstly we test whether any superannuation fund portfolio spans the space of the index returns. In other words, we test whether an investor holding a superannuation portfolio could do no better in risk-adjusted terms by adding (long positions in) the benchmark indices to his or her portfolio, following De Roon et al. (2001). The null hypothesis is that

$$
\boldsymbol{\alpha}_{i} \leqslant 0
$$

where the test statistic for $\boldsymbol{\alpha}_{i}$ is the vector of constants from the regression of excess returns to the benchmark indices $\mathbf{r}_{b, t}$ on excess returns to the fund portfolio $r_{i, t}$. The null hypothesis is written as an inequality to account for superannuation investment rules restricting funds to long-only investments. (Conventional spanning tests do not restrict the sign of portfolio weights.) If $\boldsymbol{\alpha}_{i}=0$, then the superannuation fund portfolio is as efficient as any (long-only) linear combination of the indices.

We run the least-squares regressions of index excess returns on each superannuation fund excess return

$$
\mathbf{r}_{b, t}=\boldsymbol{\alpha}_{i}+\boldsymbol{\beta}_{i} r_{i, t}+\varepsilon_{t},
$$

computing 12 equations for each of the 198 superannuation funds. We then test the null hypothesis that constants from the 12 equations are jointly zero via a Wald test using a Newey-West (1987) covariance matrix. ${ }^{17}$ (Results are reported in Figure 6.) We use critical values for the Wald test that allow for the inequality constraint, as discussed by De Roon et al. (2001) and derived by Kodde and Palm (1986).

Test results set out in Figure 6 indicate that none of the 198 fund portfolios spanned the space of index returns, which may indicate restricted or inefficient decentralized management.

As an alternative, we conduct the same spanning test against an equally weighted portfolio of indices. ${ }^{18}$ In this case the null hypothesis that $\alpha=0$ against an alternative $\alpha>0$ can be tested by a one-tailed $t$-test, and results are shown in Figure $7 .{ }^{19}$ Where the t-statistic falls below the critical value of 1.69 , we infer that the fund portfolio does at least as well as an equally weighted benchmark portfolio of indices. Of the

${ }^{17}$ See Gourieroux et al. (1982), Kodde and Palm (1986) and De Roon et al. (2001).

${ }^{18}$ On the efficiency of equally weighted portfolios, see Demiguel, Garlappi, and Uppal (2005).

${ }^{19}$ Here we automatically impose the short-sales constraint by constructing an equally weighted portfolio of benchmark assets. 


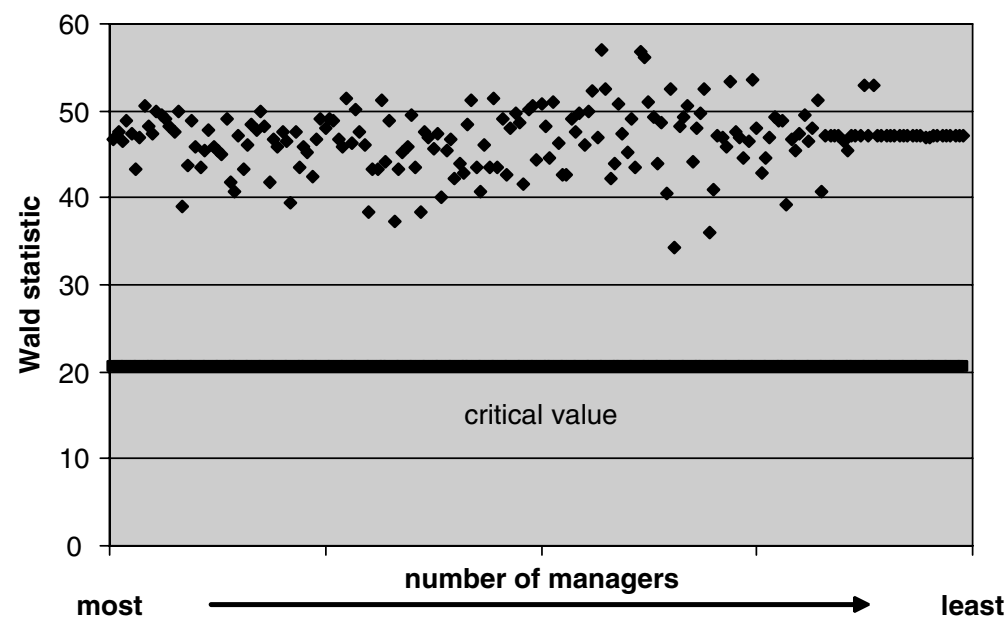

Figure 6. Unrestricted spanning tests of individual fund portfolios against asset class indices

Graph of Wald test statistics for the null hypothesis that constants in the regressions of indices against individual superannuation fund portfolios are jointly zero, i.e. that superannuation fund portfolios span the asset class indices. Critical value under short-sales constraint with 12 degrees of freedom is 20.47 according to Kodde and Palm (1986), indicating that the null is rejected for all superannuation funds.

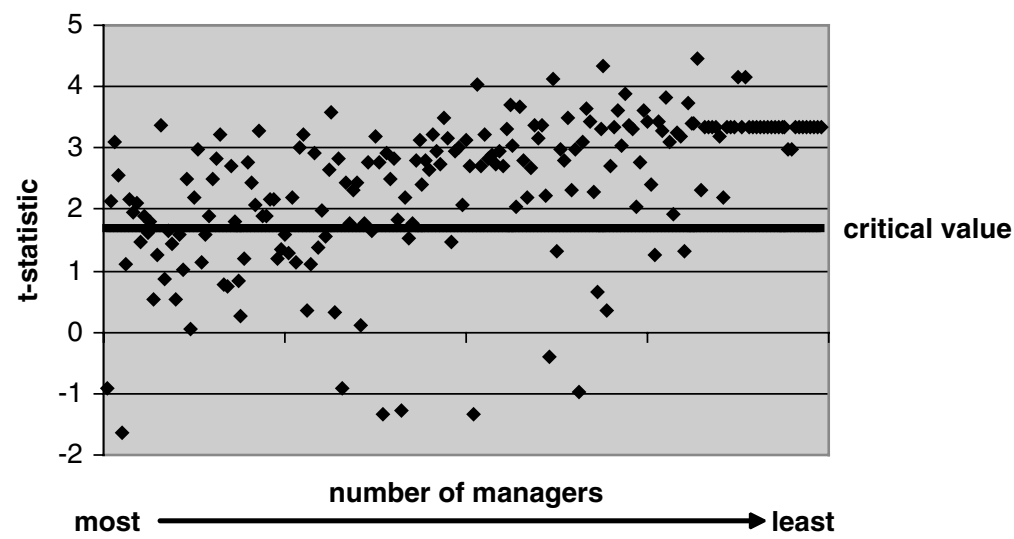

Figure 7. Spanning test of individual superannuation fund portfolios against an equally weighted portfolio of indices

Graph of t-test statistics where values below 1.69 (one-tailed $5 \%$ critical value) indicate spanning. Null hypothesis is that the constant from the regression of returns to an equally weighted portfolio of indices on returns to individual superannuation fund portfolios is zero, i.e. that fund portfolios span the equally weighted index portfolio. 
Table 6. Proportion of funds in each mandate group which span an equally weighted portfolio of indices

\begin{tabular}{lcc}
\hline \hline & $\begin{array}{c}\text { Number of } \\
\text { funds spanning }\end{array}$ & $\begin{array}{c}\text { \% of group } \\
\text { spanning }\end{array}$ \\
\hline Group 1: 22-59 mandates & 21 & 47 \\
Group 2: 13-21 mandates & 16 & 35 \\
Group 3: 6-12 mandates & 7 & 13 \\
Group 4: 1-5 mandates & 2 & 4 \\
\hline \hline
\end{tabular}

198 funds, 46 span the equally weighted benchmark, mainly funds from the higher mandate groupings. In fact, almost half of the 22-59 mandate group span the equally weighted benchmark, and more than one third of the 13-21 mandate group (See Figure 7). However, in terms of terminal wealth over 20 years, a superannuation portfolio which returned the average of the 198 represented here would generate around $16 \%$ less than funds invested in the equally weighted benchmark portfolio.

In summary, superannuation fund portfolio returns appear less efficient than an optimally weighted long-only portfolio of indices, but about one quarter of superannuation funds perform at least as well as an equally weighted portfolio of indices. Funds having more than 13 mandates are more likely to match equally weighted benchmark performance, and the probability of matching the index rises as mandates rise above 21 .

\subsection{Do fund trustees choose managers with skill?}

To gauge the ability of trustees to choose from the universe of investment managers we test randomly selected portfolios from the investment manager pool against the equally weighted benchmark. There are a total of 362 specialized investment managers whose returns are available in the Rainmaker database. Of these, 114 are Australian equities managers, 47 are Australian fixed interest managers, 49 are Australian property managers, 121 are international equities managers, 26 are international fixed interest managers, and five are hedge funds. (We leave diversified managers out of the simulation.) We form 100 random selections of pre-specified size from this pool of managers and then compute equally weighted portfolio returns using realized returns for the randomly selected managers. We test returns from simulated portfolios against the returns from an equally weighted benchmark for spanning, and we report the proportion of the 100 simulations for which we could not reject the null hypothesis of $\alpha=0$ against the one-sided alternative $\alpha>0$.

In the first round we allow random selections from the pool of investment managers to be unconstrained, with all managers equally likely to be selected (Table 6). Unconstrained random selection does mean, however, that the asset classes with the highest representation in the Rainmaker manager pool are most likely to be selected. Since the largest group is international equity managers, which generated poor returns over this sample, it is perhaps not surprising to find that when we add more managers to a portfolio, performance against the benchmark worsens. 


\section{Table 7. Spanning tests of randomly selected portfolios of investment funds}

Random selection of investment funds were made from the mandate manager pool and formed into equally weighted portfolios. The first column reports the proportion of these funds spanning the equally weighted portfolio of indices from 100 hundred simulations where any combination of investment managers could be chosen. The second column reports the proportion of these funds spanning when the random selections were constrained to choose at least one manager from Australian equity, fixed interest and property, and international equity and fixed interest, and then make random selections for remaining funds.

\begin{tabular}{lcc}
\hline \hline & \% of simulated portfolios spanning index portfolio \\
\cline { 2 - 3 } $\begin{array}{l}\text { Number of funds } \\
\text { per portfolio }\end{array}$ & Random selection & $\begin{array}{c}\text { Asset class }+ \\
\text { random selection }\end{array}$ \\
\hline 6 & 41 & 66 \\
8 & 35 & 60 \\
10 & 31 & 55 \\
12 & 32 & 46 \\
14 & 29 & 52 \\
16 & 28 & 43 \\
18 & 29 & 40 \\
20 & 27 & 33 \\
\hline \hline
\end{tabular}

Compared with the actual outcomes for the superannuation portfolios, however, the random selection process uncovers some interesting features. The proportion of portfolios spanning the equally weighted index portfolio is much higher among random selections in the 6-12 manager (mandate) range (above 30\%) than it is among actual superannuation portfolios in this mandate range $(13 \%)$. By contrast, randomly selected portfolios in the 13-21 range show lower likelihood of spanning than the actual superannuation portfolios in this range $(29 \%$ as compared with $35 \%$ ), and given the downward trend in the random selection spanning rates, the top-end group of actual superannuation portfolios did better.

In the second round (see Table 7) we forced the allocation to include at least one randomly selected investment manager from Australian equity, fixed interest, and property, and international equity and fixed interest. After selecting a manager from each of those asset class groups, we added managers at random without restrictions. Forcing asset class diversification greatly increases the likelihood that a randomly selected portfolio of managers will test well against the equally weighted benchmark, but again the likelihood of spanning declines as managers are added. The performance of the actual superannuation portfolios is worse than the asset-class-diversified random selections for all but the high-mandate group.

To summarize, these simulation exercises indicate that trustees of superannuation funds with more than 13 mandates did better than a randomly selected, equally weighted portfolio, drawing from the same pool of investment managers. Results were less convincing when we constrained random selections to minimal asset class diversification. In that case, only the superannuation funds with the largest 


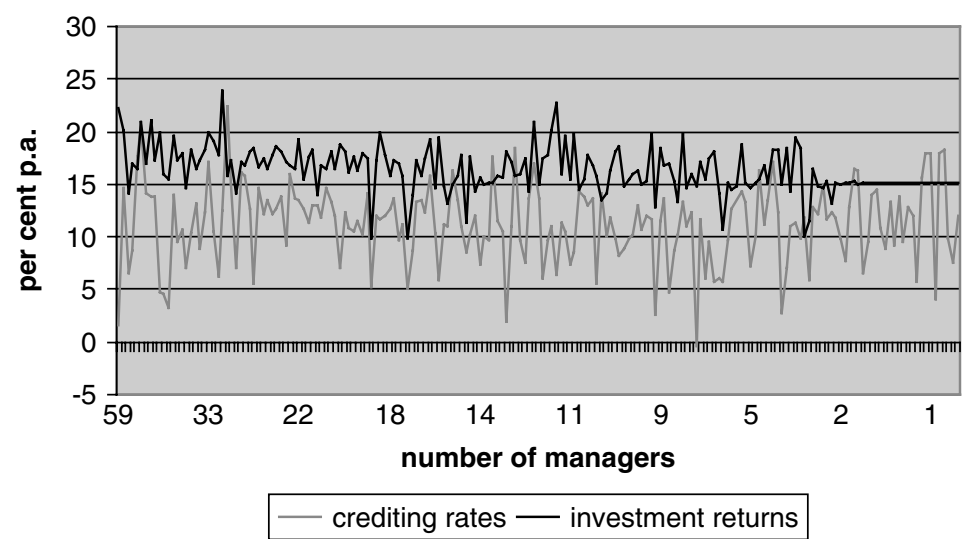

Figure 8 . Reported crediting rate and investment return for the year to June 2004

Crediting rates calculated as a value-weighted average of crediting rates to member 'options' where values were available; otherwise as an equally weighted average of reported crediting rates. Funds not reporting any crediting rates were omitted. Investment returns calculated as a value-weighted average of returns to individual mandates.

Source: Rainmaker database.

number of mandates could perform better than equally weighted, diversified random selection.

We can think of these choices as analogous to an uninformed individual selecting from a 401(k) plan menu. These results show that trustee selections are no better over this sample than a random application of a simple diversification strategy, choosing a manager from each asset class and building an equally weighted portfolio.

\subsection{Investment returns and member account crediting}

Of ultimate concern to superannuation fund members is not the raw investment returns available to trustees for distribution, but returns credited to member accounts. Here we compare averages of reported crediting rates for the year to June 2004, with the annual raw investment return gained over the same year. ${ }^{20}$ Series for individual funds are shown in Figure 8.

Figure 8 shows that the correlation between gross investment returns and crediting rates is remarkably weak at the individual fund level (correlation coefficient is 0.12). Accounting for some gap between investment returns and crediting rates is not so difficult: manager fees, taxes, administrative expenses, and other costs all may contribute to differences between investment earnings and crediting rates. What is harder to explain is the volatility of the gap between the two series on a fund by fund

${ }^{20}$ Most superannuation funds report crediting rates annually. The self-reported crediting rates shown in Figures 8 and 9 are taken from Rainmaker Marketplace. Where information on the proportion of total funds held in each account option was available, the crediting rate is a weighted average of separate account crediting rates. If funds did not report option weights, then a simple average of crediting rates is reported. 


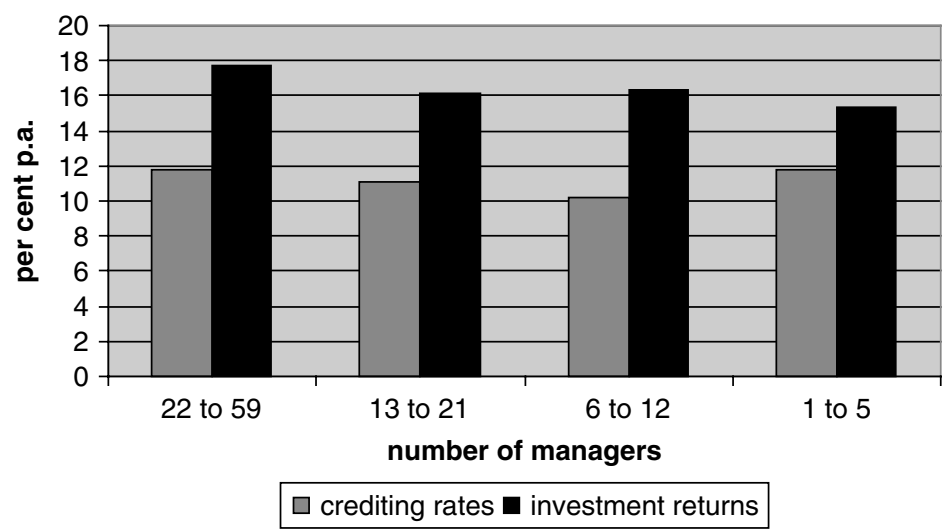

Figure 9. Average of crediting rates and investment returns for large to small mandate groups

Crediting rates and investment returns calculated according to data in Figure 3 and averaged across each mandate group.

Source: Rainmaker database.

basis, since one would expect most not-for-profit superannuation funds to face similar taxes, fees, and expenses, conditional on asset allocation. ${ }^{21}$

Grouping the funds and averaging as we do in Figure 9 smooths away the volatility, but exposes another anomaly: while the 22-59 mandate group generates the highest gross investment return, it does no better on crediting rates than the 1-5 mandate group (11.8 as compared with $11.75 \%$ p.a.). The lowest crediting rates apply to the 6-12 mandate group (10.21\% p.a.), but the actual variation from group to group is small.

We cannot draw a strong conclusion from this single and approximate data point, but these results do raise doubts as to how much of any diversification benefits from mandate proliferation is being passed on to members of superannuation funds.

\section{Conclusions}

Theory suggests that the task of combining decentralized investments is difficult without full information and is likely to lead to inefficiencies except under special conditions. Managers of large pools of funds in financial markets behave as if the opposite were true. In the USA, for example, sponsors and administrators of 401(k) plans act as a filter on the mutual fund industry, selecting a group of managers that plan members may invest in. For Australia, the trustees of not-for-profit superannuation funds are responsible for investing contributions, and increasingly have delegated to specialized investment managers via investment mandates. In this study we evaluate the additional layer of management undertaken by non-profit pension fund trustees via a series of statistical comparisons and performance tests.

${ }^{21}$ Reserving and returns smoothing are not likely explanations of the weak relationship evident in Figure 8. A regression (not reported here) of the 2004 crediting rate on investment returns from the current and previous two years did not find any significant relationship between 2004 crediting rates and investment returns from 2003 and 2002. 
Using a unique data set from Rainmaker Information, we create mandate-based investment portfolio returns for 198 not-for-profit superannuation funds, generating 36 monthly investment returns for each fund for the three years to December 2004.

Firstly, we establish a positive link between higher investment returns and higher numbers of delegated management, but the relationship is not linear. Results of portfolio against portfolio comparisons suggest that superannuation fund trustee boards which employ more than 13 managers did better on a risk-adjusted-return basis than funds with fewer managers. The differences in risk are statistically significant between the groups with 13 or more managers and those with less, but no significant difference can be detected for those funds with 6-12 managers and those with fewer. Worst performance over the sample period is associated with funds that had 6-12 managers.

Secondly, the combined portfolios of delegated investments do not appear to span an optimally invested portfolio of asset-class indices. When we compare superannuation portfolio returns with returns to a group of standard asset class indices, spanning tests showed that none of the 198 funds were as efficient as an optimally long-weighted portfolio of indices. Superannuation portfolios with 22-59 mandates did perform as well as an equally weighted portfolio of indices in about $50 \%$ of cases, and about $30 \%$ of cases for portfolios made up of 13-21 mandates. This compares with the findings of Elton, Gruber, and Blake (2004) that about $38 \%$ of $401(\mathrm{k})$ plans in their sample spanned the returns space of eight asset class indices.

Thirdly, when we build portfolios of randomly selected investment managers from the pool available to superannuation fund trustees, results show that actual superannuation portfolios with many mandates did better than the randomly generated equally weighted portfolios, but those with fewer mandates did worse. However once we constrain the randomly generated portfolios to match minimal asset class diversification, actual portfolio performance was rarely better than chance selection. Results show that actual trustee selections are not significantly better over this sample than a simple diversification strategy of choosing at least one manager from each asset class at random.

Taken as a whole, the evidence for mandate-based delegated investment in the Australian retirement savings system is mixed. Compared with other superannuation funds, funds with very high rates of mandate issuance add value in gross risk-adjusted returns, and probably perform as well as an equally weighted benchmark portfolio. However these advantages appear to accrue only to funds with very large and sophisticated delegation structures. On the contrary, adding a few specialist managers to a passively diversified portfolio does not appear to improve it and does no better than random selection over the sample we investigate. What is not at all clear at this stage of research is the extent to which gains to mandated investment are diluted by the higher expense of engaging and administering large and complex portfolios.

Data constraints have so far prevented us conducting a rigorous comparison between crediting rates to members' retirement savings accounts and actual investment returns, but using the little data that is available raises some puzzles. The correlation between crediting rates and investment returns is very low at the individual fund level. When we pool investment returns and crediting rates into 
quartile mandate groups, we find that diversification gains from employing more investment managers may be being consumed in fees, costs, or smoothing. We plan to unpack the links between actual crediting rates and gross investment returns in future research.

Finally, we plan to extend this analysis to the Australian retail superannuation sector which does not employ trustees to select managers. Instead, retail fund members directly allocate savings across a menu of investment options in a manner closer to participants in $401(\mathrm{k})$ plans. In future research we will compare the relative merits of trustee-directed with member-selected investment for pension funds within the same jurisdiction.

\section{References}

APRA (1999) Managing investments and investment choice. Superannuation Circular no.II.D.1., Australian Prudential Regulation Authority, Sydney.

APRA (2005) Statistics - Quarterly Superannuation Performance, March 2005. http:// www.apra.gov.au/Statistics/

Bateman, H. and R. Hill (2004) Benchmarking the performance of mutual funds. Paper presented to the 12th Australian Colloquium of Superannuation Researchers, July 2004, UNSW, Sydney.

Barrett, G. F. and S. G. Donald (2003) Consistent tests for stochastic dominance. Econometrica, 71(1): 71-104.

Brands, S. and D. J. Gallagher (2003) A note on portfolio selection, diversification and fund of funds. UNSW School of Banking and Finance Working Paper 17-03. University of New South Wales, Sydney.

Brown J. R. and S. Weisbenner (2005) The effects of portfolio choice on retirement wealth outcomes. presented to the RRC Annual Conference, Washington DC, August 2005.

Chen, Z. and P. J. Knez (1996) Portfolio performance and measurement: theory and applications. Review of Financial Studies, 9(2): 511-555.

Cogan, J. and O. S. Mitchell (2003) Perspectives from the President's Commission on Social Security Reform. Journal of Economic Perspectives, 17(2): 149-172.

Demiguel, A.-V., L. Garlappi, and R. Uppal (2005) How inefficient is the $1 / \mathrm{N}$ asset allocation strategy? CEPR Discussion Paper No. 5142, Centre for Economic Policy Research, London Business School, London.

De Roon, F. A., T. E. Nijman, and B. J. M. Werker (2001) Testing for mean-variance spanning with short sales constraints and transactions costs: the case of emerging markets. Journal of Finance, 56(2): 721-742.

Elton, E. J. and M. J. Gruber (2004) Optimum centralized portfolio construction with decentralized portfolio management. Journal of Financial and Quantitative Analysis, 39(3): 481-494.

Elton, E. J., Gruber, M. J., and Blake, C. R. (2004) The adequacy of investment choices offered by 401(k) plans. Working Paper No. SC-AM-03-10, Salomon Center for the Study of Financial Institutions, Stern School, New York University (forthcoming, Journal of Public Economics).

Gourieroux, C., A. Holly, and A. Monfort (1982) Likelihood ratio test, Wald test, and Kuhn-Tucker test in linear models with inequality constraints on the regression parameters. Econometrica, 50(1): 63-80.

Kodde, D. A. and Palm, F. C. (1986) Wald criteria for jointly testing equality and inequality restrictions. Econometrica, 54(5): 1243-1248.

Lim, G. C., E. Maasoumi, and V. L. Martin (2004) Discounting the equity premium puzzle, unpublished manuscript. Economics Department, University of Melbourne, Victoria. 
Mitchell, O. S., S. P. Utkus, and T. Yang (2005) Better plans for the better paid: determinants and effects of 401(k) pension plan design. PRCWP 2005-5, Pension Research Council, The Wharton School.

Newey, W. and K. West (1987) A simple positive definite heteroskedasticity and autocorrelation consistent covariance matrix. Econometrica, 55(3): 703-705.

Palme, M., A. Sunden, and P. Sonderlind (2005) Investment choice in the Swedish Pension Plan. Centre of Retirement Research, Boston College, Working Paper 2005-06.

Papke, L. E. (2004) Choice and other determinants of employee contributions to defined contribution plans. CRR Working Paper 2004-06, Centre for Retirement Research at Boston College, Boston.

Rainmaker (2004) Mandate pipeline analysis: superannuation mandates 2003-4. Rainmaker Information, Sydney, February 2004.

Sharpe, W. F. (1981) Decentralized investment management. Journal of Finance, 36(2): 217-234.

Sunden, A. (2004) How do individual accounts work in the Swedish Pension System? An issue in brief. Center for Retirement Research, Boston College, August 2004, No. 22.

Treynor, J. L. and F. Black (1973) How to use security analysis to improve portfolio selection. Journal of Business, 46(1): 56-86.

\section{Appendix A: Benchmark data}

\section{Australia:}

- Large-cap equities: S\&P/ASX 50 total returns index ASX5LD(RI) A S, DataStream

- Mid-cap equities: S\&P/ASX MIDCAP50 total returns index ASXM50I(RI) AS, DataStream

- Small-cap equities: ASX Small ordinaries total returns index ASXSORD(RI) $\sim$ AS, DataStream

- Value equities: MSCI Australia Value Gross Index, local currency, MSCI http://www.msci.com/equity/index2.html

- Growth equities: MSCI Australia Growth Gross Index, local currency, MSCI http://www.msci.com/equity/index2.html

- Property: GPR General PSI Australia total returns index GPRGALL(RI) $\sim \mathrm{A} \$$, DataStream

- Cash: UBS Australian Bank Bills ABNKBLI(PI) A \$, DataStream

- Fixed Interest composite: UBS Composite All Maturities total returns index, ACIALL(RI) A $\$$, DataStream

- Fixed Interest indexed: UBS Govt. Inflation All Maturities total returns index, AIALLM(RI) A \$, DataStream

\section{International:}

- World equities: World ex Australia Gross Index, local currency, MSCI http:// www.msci.com/equity/index $2 . h t m l$

- Emerging markets: MSCI Emerging markets total returns index, $\operatorname{MSEMKF}(\mathrm{RI}) \sim \mathrm{A} \$$, DataStream

- Fixed Interest: Salomon Bros. CGBIWGBI All Maturities (A\$ Hedged) SBWGTCA $(\mathrm{RI}) \sim \mathrm{A} \$$, DataStream

\section{Risk-free rates:}

- Australian 30 day Bank Bill rate, end month, Reserve Bank of Australia Bulletin Database, http://www.rba.gov.au/Statistics/Bulletin/index.html\#table_f 